\title{
Unil
}

UNIL | Université de Lausanne

Unicentre

$\mathrm{CH}-1015$ Lausanne

http://serval.unil.ch

Year : 2021

\section{Trends in prevalence and outcomes of frailty in a Swiss university hospital: A retrospective observational study}

\author{
Bonjour Thierry
}

Bonjour Thierry, 2021, Trends in prevalence and outcomes of frailty in a Swiss university hospital: A retrospective observational study

Originally published at : Thesis, University of Lausanne

Posted at the University of Lausanne Open Archive http://serval.unil.ch

Document URN : urn:nbn:ch:serval-BIB_6DD8B3A2F1686

\section{Droits d'auteur}

L'Université de Lausanne attire expressément l'attention des utilisateurs sur le fait que tous les documents publiés dans I'Archive SERVAL sont protégés par le droit d'auteur, conformément à la loi fédérale sur le droit d'auteur et les droits voisins (LDA). A ce titre, il est indispensable d'obtenir le consentement préalable de l'auteur et/ou de l'éditeur avant toute utilisation d'une oeuvre ou d'une partie d'une oeuvre ne relevant pas d'une utilisation à des fins personnelles au sens de la LDA (art. 19, al. 1 lettre a). A défaut, tout contrevenant s'expose aux sanctions prévues par cette loi. Nous déclinons toute responsabilité en la matière.

\section{Copyright}

The University of Lausanne expressly draws the attention of users to the fact that all documents published in the SERVAL Archive are protected by copyright in accordance with federal law on copyright and similar rights (LDA). Accordingly it is indispensable to obtain prior consent from the author and/or publisher before any use of a work or part of a work for purposes other than personal use within the meaning of LDA (art. 19, para. 1 letter a). Failure to do so will expose offenders to the sanctions laid down by this law. We accept no liability in this respect. 


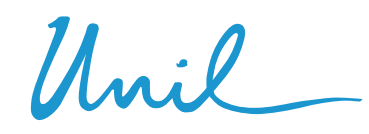

UNIL | Université de Lausanne

Faculté de biologie

et de médecine

UNIVERSITE DE LAUSANNE - FACULTE DE BIOLOGIE ET DE MEDECINE

Département de médecine

Service de médecine interne

Trends in prevalence and outcomes of frailty in a Swiss university hospital: A retrospective observational study

\section{THESE}

préparée sous la direction du Professeur Gérard Waeber avec la collaboration du Professeur Pedro-Manuel Marques-Vidal

et présentée à la Faculté de biologie et de médecine de

I'Université de Lausanne pour l'obtention du grade de

DOCTEUR EN MEDECINE

par

Thierry BONJOUR

Médecin diplômé de la Confédération Suisse

Originaire de Blonay (Vaud) 


\section{Imprimatur}

Vu le rapport présenté par le jury d'examen, composé de

Directeur de thèse

Prof. Gérard Waeber

Co-Directeur de thèse

Expert

Prof. Christophe Büla

Vice-Directeur de I'Ecole Prof. John Prior doctorale

la Commission MD de l'Ecole doctorale autorise l'impression de la thèse de

\section{Monsieur Thierry Bonjour}

intitulée

Trends in prevalence and outcomes of frailty in a Swiss

university hospital: A retrospective observational study

Lausanne, le 11 février 2021

pour Le Doyen

de la Faculté de Biologiøet de Médecine

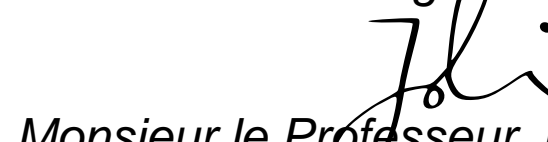

Monsieur le Prefesseur John Prior

Vice-Directeur de l'Ecole doctorale 


\title{
Trends in prevalence and outcomes of frailty in a Swiss university hospital: a retrospective observational study
}

\author{
Thierry Bonjour, Gérard Waeber, Pedro Marques-Vidal \\ Department of Medicine and Internal Medicine, Lausanne University Hospital (CHUV), Lausanne, Switzerland
}

Address correspondence to: Pedro Marques-Vidal, Office BH 10-642, Service de médecine interne, Centre hospitalier universitaire vaudois, Rue du Bugnon 46, 101 I Lausanne, Switzerland. Tel: (+4I) 2131409 34; Email:Pedro-Manuel.Marques-Vidal@chuv.ch

\begin{abstract}
Background: Frailty complicates management and worsens outcomes. We assessed the prevalence, determinants and consequences of frailty among elderly patients in a hospital setting.

Design: Retrospective observational study in a Swiss university hospital.

Methods: 22,323 patients aged $\geq 65$ years hospitalized between January 2009 and December 2017 at the internal medicine ward were included. Frailty was defined by the Hospital Frailty Risk Score (HFRS) and patients were categorized as low (HFRS $<5$ ), intermediate (HFRS 5-15) and high (HFRS > 15) risk.

Results: Overall prevalence of intermediate and high risk of frailty was $43 \%$ and $20 \%$, respectively; prevalence was higher in women and increased with age. Prevalence of high risk of frailty increased from $11.4 \%$ in 2009 to $31 \%$ in 2012 , and decreased to $19.2 \%$ in 2017 . After multivariable adjustment, frailty was associated with increased length of stay: average and (95\% confidence interval) 11.9 (11.7-12.1), $15.6(15.4-15.8)$ and 19.7 (19.3-20.1) days for low, intermediate and high risk, respectively, and increased likelihood of ICU stay: odds ratio (OR) and (95\% CI) 1.57 (1.41-1.75) and 2.10 (1.82-2.42) for intermediate and high risk, respectively, $\mathrm{p}$ for trend $<0.001$. Frailty was associated with increased likelihood of hospital costs >70,000 CHF: OR and (95\% CI) 3.46 (2.79-4.29) and 10.7 (8.47-13.6) for intermediate and high risk, respectively, $\mathrm{p}$ for trend $<0.001$, and with a lower likelihood of complete cost coverage: OR and (95\% CI) 0.70 (0.65-0.76) and 0.52 $(0.47-0.58)$ for intermediate and high risk, respectively, $p$ for trend $<0.001$.
\end{abstract}

Conclusions: Frailty is a frequent condition among hospitalized patients and is associated with higher costs.

Keywords: frailty, patients, health costs, Switzerland, retrospective study, older people

\section{Key Points}

- Frailty trends is a retrospective study on 22,323 patients aged $\geq 65$ years.

- Of these patients, $43 \%$ were at intermediate and $20 \%$ at high risk of frailty.

- High risk of frailty increased length of stay, hospital costs and risk of intensive care unit stay.

\section{Introduction}

It is estimated that by year 2050 circa two billion people aged over 65 years will populate the world [1]. In some parts of Switzerland, the number of people aged over 65 is expected to double, representing one-quarter of the total population [2]. This increase poses a considerable pressure in the hospital setting, where increasingly older and more frail patients are admitted. Frailty can be defined by a state of vulnerability following a stress and is a consequence of cumulative decline in multiple physiological systems eroding homeostatic reserve until relative minor stressor events trigger disproportionate changes in health status [3]. In 2005, Rockwood et al. [4] published the Clinical Frailty Scale (CFS), grading frailty 


\section{T. Bonjour et al.}

on a 7-point scale ranging from 1 (very fit) to 7 (severely frail). Although many other tools to assess frailty have been described since, there is still no gold standard for frailty detection [5]. This multiplicity of available tools has led to widely differing values for the prevalence of frailty, ranging from 10 to $23 \%$ among patients aged over $65[6,7]$.

Frailty is an important and independent risk factor for mortality [8], lower quality of life [9], increased hospital length of stay (LOS) [10] and costs [11], increased risk of nursing home admission [10] and rehospitalisation [12]. This high burden of frailty on the health system raises the issue of a systematic screening of frailty in older people, the effectiveness of which is currently debated [13]. Indeed, the effectiveness of such a screening is dependent on the screening tool used, which should be easy to apply and with a high sensitivity and specificity. The tools cited earlier do not fulfil these criteria, for instance, the frailty phenotype [14] is time consuming and includes measurements not routinely used for patient assessment like gait speed or grip strength; the Clinical Frailty Scale [4] is dependent on clinical appreciation, and the Frailty Index [15] has not been validated in hospital settings. Recently, Gilbert et al. [16] proposed the Hospital Frailty Risk Score (HFRS) to assess frailty in the acute care setting. To our knowledge, the HFRS is the only tool developed for a hospital setting. Recently, the prognostic value of the HFRS has been validated on an independent patient population and confirmed the ability of the score to identify patients at risk of adverse outcomes [17].

Hence, we aimed to (1) evaluate the prevalence and the 9-year evolution of frailty (as defined by the HFRS) in patients aged $\geq 65$ years hospitalised on the internal medicine ward of the Lausanne University Hospital (CHUV) and (2) study the association between frailty and LOS, in-hospital mortality, intensive care unit (ICU) stay, early readmissions and hospital costs. We hypothesised that the prevalence of frailty would increase and would be associated with all deleterious outcomes and increased costs.

\section{Patients and methods}

\section{Setting}

This is a retrospective study using medical information from of the Department of Internal Medicine of the CHUV. The CHUV is one of the Swiss university hospitals (www.chuv. ch), and the internal medicine unit of the CHUV is the largest in Switzerland, with over 4,000 admissions per year. The CHUV serves both as an end-stage hospital and as a general hospital for the population of canton Vaud.

\section{Participants}

We included all patients aged 65 or more, hospitalised between January 2009 and December 2017. Over four out of five admissions to the internal medicine ward transit via the emergency department.

\section{Methods}

Coded data was extracted from the hospital medical records by an independent office in charge of data extraction and coding at the CHUV. The following information was extracted: gender, age, number of diagnoses at discharge (coded according to the 10th International Classification of Diseases of the World Health Organization-ICD-10), LOS (in days), stay in an ICU (yes/no), status at discharge (death, return home or institutionalised), 30-day, 90-day and 1-year mortality, and total and reimbursable costs. Mortality data was obtained from the population registries, which record the vital status of a person (i.e. alive/death) but not the cause of death.

We computed the Charlson risk score according to an algorithm optimised for Switzerland [18] and categorised the participants into $0,1-2,3-4$ and $5+$ as suggested in the original publication [19].

The rate of readmission was computed taking into account the 1st admission for each patient within the 2004 17 period, admissions occurring 30 days after the 1st one were considered.

Due to changes in the Swiss reimbursement system by the introduction of the Diagnosis Related Groups (DRG), reimbursable costs were obtained only for years 2012 onwards. Total costs were categorised into $<70,000$ and $\geq 70,000$ Swiss franc (CHF); this limit was chosen as it is the approximated cost of 1 year of chronic haemodialysis in Switzerland [20]. The difference between total and reimbursed costs was computed and categorised as fully covered if the difference was $\geq 0$. Cost of stay was further categorised according to the DRG criteria into lowlier (LOS below the low margin of LOS for the corresponding DRG), inlier (within the low and high margins of LOS for the corresponding DRG) or highlier (above the high margin of LOS for the corresponding DRG).

\section{Risk of frailty}

Risk of frailty was defined according to HFRS proposed by Gilbert et al. [16]. The HFRS is a sum of different ICD-10 codes, which are weighted according to their clinical impact. The weight for each condition is provided in Supplementary Table S1. For each admission, the HFRS was computed based on ICD codes and categorised into low $(<5)$, intermediate $(5-15)$ and high $(>15)$ risk.

\section{Ethical statement}

The Ethics Commission of Canton de Vaud (www.cer-vd. ch) approved the study protocol (decision No. 2018-01689 of 11 October 2018). The full decision of the CER-VD can be obtained from the authors upon request. The study was performed in agreement with the Helsinki declaration and its former amendments, and in accordance with the applicable Swiss legislation. No individual informed consent was deemed necessary. 


\section{Statistical analysis}

Statistical analysis was performed using Stata version 16.1 for windows (Stata Corp, College Station, TX, USA). Descriptive results were expressed as number of participants (percentage) or as average \pm standard deviation (SD). Bivariate analyses were performed using chi-square test for qualitative variables and analysis of variance or Kruskal-Wallis test for continuous variables.

Trends in prevalence of intermediate and high risk of frailty were assessed using multinomial logistic regression and the results were expressed as multivariable-adjusted relative risk ratios and 95\% confidence interval (95\% CI). For categorical variables, multivariable analysis was conducted using logistic regression and results were expressed as odds ratio and 95\% CI. For continuous variables, multivariable analysis was conducted using analysis of variance and results were expressed as multivariable-adjusted average and 95\% CI. Due to the skewed distribution of LOS and health costs, negative binomial regression was performed. Survival analysis was conducted using Cox regression and results were expressed as hazard ratios and 95\% CI. All multivariable models were adjusted on gender (man, woman), age group $(65-74,75-84,85+)$, number of previous hospitalisations (continuous) and Charlson index categories $(0,1-2,3-4$, $5+)$. Further adjustments on year of discharge, ICU stay (yes, no) and LOS (quartiles) were performed whenever necessary. Trends within the different frailty groups were tested using the 'contrast p.' command of Stata.

As participants could be hospitalised several times during the study period, a 1st sensitivity analysis was performed considering only the 1st hospitalisation. As the HFRS uses data from the previous 2 years, a 2 nd sensitivity analysis was performed considering only the period 2011-17. Due to the number of tests performed, statistical significance was assessed for a two-sided test with $P<0.001$.

\section{Results}

\section{Characteristics of patients admitted according to frailty categories}

Overall, 22,323 admissions were included (52\% women, mean $\pm S D$ age $80.2 \pm 8.2$ years). Prevalence of frailty, defined as an intermediate or high HFRS, was 63\% $(95 \%$ CI: 62.7-64.0), with $43 \%(N=9,656)$ in the intermediaterisk and $20 \%(N=4,485)$ in the high-risk groups.

The characteristics of the patients admitted overall and according to frailty category are summarised in Table 1. Patients at intermediate or high risk of frailty were more frequently women, were older, presented more frequently with a main diagnosis of gait problems, delirium and sepsis, and less frequently with a main diagnosis of acute myocardial infarction and chronic obstructive pulmonary disease than patients at low risk. Regarding types of disease, patients at intermediate or high risk of frailty presented more frequently with pneumonia, gait problems, delirium, sepsis, chronic kidney disease, diabetes and hypertension, and less frequently with a main diagnosis of acute myocardial infarction and chronic obstructive pulmonary disease than patients at low risk. Finally, patients at intermediate or high risk of frailty had a higher number of comorbidities and were more frequently in the 3-4 and 5+ categories of the Charlson index (Table 1).

\section{Evolution of frailty between 2009 and 2017}

The trends between 2009 and 2017 for prevalence of the intermediate- and the high-risk categories of frailty are represented in Figure 1. There was an increase in the prevalence of high-risk patients from 2009 to 2012, followed by a sharp decrease afterwards. This evolution was further confirmed after multivariable adjustment (Figure 2).

\section{Association between frailty and LOS, ICU stay, mortality and costs}

The bivariate associations between frailty categories and destination after hospitalisation, ICU stay, LOS, readmission, hospital costs, and 30-, 90-day and 1-year mortality are summarised in Table 2. Patients at intermediate or high risk of frailty were more frequently admitted to the ICU, spent more time in the ICU and were more frequently institutionalised after discharge than patients at low risk. Patients at high risk of frailty had a higher 30-day, 90-day and 1-year mortality than patients at low risk. Patients at intermediate or high risk had higher total and reimbursed costs, their stay was less frequently fully covered and they were more frequently highliers than patients at low risk.

The multivariable associations between frailty categories and ICU stay, LOS, readmission, hospital costs, and 30-, 90- and 1-year mortality are summarised in Supplementary Table S2. Overall, the results were similar to those from the bivariate analyses, except that the associations with 30-day mortality were no longer significant. Further adjusting on ICU stay and LOS led to similar findings, except that the differences regarding cost coverage were no longer significant (Supplementary TableS3). Finally, adjusting for number of previous hospitalisations showed frailty levels to be positively associated with 30-, 90- and 1-year mortality (Table 3).

\section{Sensitivity analysis}

The results of the analyses using only 1st admissions are summarised in Supplementary Tables S4-S6. On bivariate analysis, patients at intermediate or high risk of frailty were more frequently admitted to the ICU, spent more time in the ICU and were more frequently institutionalised after discharge than patients at low risk. No differences were found regarding 30- and 90-day mortality, whereas patients at intermediate or high risk of frailty had a higher 1-year mortality than patients at low risk. Patients at intermediate or high risk had a higher total and reimbursed costs, their stay was less frequently fully covered and they were more frequently 


\section{T. Bonjour et al.}

Table I. Clinical characteristics overall and according to the different frailty risk categories, Lausanne University Hospital, Lausanne, Switzerland, 2009-17

\begin{tabular}{|c|c|c|c|c|c|}
\hline & Total & Low & Intermediate & High & $P$-value \\
\hline$N$ & 22,323 & 8,182 & 9,656 & 4,485 & \\
\hline Women (\%) & $11,579(51.9)$ & $4,000(48.9)$ & $\begin{array}{l}5,139 \\
(53.2)\end{array}$ & $2,440(54.4)$ & $<0.001$ \\
\hline $\begin{array}{l}\text { Age (years) } \\
\text { Age group (\%) }\end{array}$ & $80.2 \pm 8.2$ & $78.2 \pm 8.1$ & $81.0 \pm 8.1$ & $82.2 \pm 7.8$ & $\begin{array}{l}<0.001 \\
<0.001\end{array}$ \\
\hline $65-74$ & $6,121(27.4)$ & $2,950(36.1)$ & $\begin{array}{l}2,340 \\
(24.2)\end{array}$ & $\begin{array}{l}831 \\
(18.5)\end{array}$ & \\
\hline $75-84$ & $8,621(38.6)$ & $3,170(38.7)$ & $\begin{array}{l}3,699 \\
(38.3)\end{array}$ & $1,752(39.1)$ & \\
\hline $85+$ & $7,581(34.0)$ & $2,062(25.2)$ & $\begin{array}{l}3,617 \\
(37.5)\end{array}$ & $1,902(42.4)$ & \\
\hline Main diagnosis (\%) & & & & & $<0.001$ \\
\hline Heart failure & $2,123(9.5)$ & $822(10.1)$ & 857 (8.9) & $444(9.9)$ & \\
\hline Pneumonia & $1,643(7.4)$ & $633(7.7)$ & $709(7.3)$ & $301(6.7)$ & \\
\hline Gait problems & $922(4.1)$ & $61(0.8)$ & $501(5.2)$ & $360(8.0)$ & \\
\hline Delirium & $800(3.6)$ & $34(0.4)$ & $364(3.8)$ & $402(9.0)$ & \\
\hline Sepsis & $755(3.4)$ & $110(1.3)$ & $377(3.9)$ & $268(6.0)$ & \\
\hline Acute myocardial infarction & $656(2.9)$ & $327(4.0)$ & $256(2.7)$ & $73(1.6)$ & \\
\hline COPD & $642(2.9)$ & $315(3.9)$ & $244(2.5)$ & $83(1.9)$ & \\
\hline Diabetes & $179(0.8)$ & $73(0.9)$ & $73(0.8)$ & $33(0.7)$ & \\
\hline Other & $14,603(65.4)$ & $5,807(71.0)$ & $\begin{array}{l}6,275 \\
(65.0)\end{array}$ & $2,521(56.2)$ & \\
\hline \multicolumn{6}{|l|}{ Presence of (\%) } \\
\hline Heart failure & $3,840(17.2)$ & $1,243(15.2)$ & $\begin{array}{l}1,699 \\
(17.6)\end{array}$ & $\begin{array}{l}898 \\
(20.0)\end{array}$ & $<0.001$ \\
\hline Pneumonia & $1,817(8.1)$ & $472(5.8)$ & $870(9.0)$ & $475(10.6)$ & $<0.001$ \\
\hline Gait problems & $4,013(18.0)$ & $\begin{array}{l}261 \\
(3.2)\end{array}$ & $\begin{array}{l}2,103 \\
(21.8)\end{array}$ & $1,649(36.8)$ & $<0.001$ \\
\hline Delirium & $2,281(10.2)$ & $\begin{array}{l}128 \\
(1.6)\end{array}$ & $\begin{array}{l}1,140 \\
(11.8)\end{array}$ & $1,013(22.6)$ & $<0.001$ \\
\hline Sepsis & $854(3.8)$ & $114(1.4)$ & $428(4.4)$ & $312(7.0)$ & $<0.001$ \\
\hline Acute myocardial infarction & $\begin{array}{l}525 \\
(2.4)\end{array}$ & $\begin{array}{l}159 \\
(1.9)\end{array}$ & $\begin{array}{l}234 \\
(2.4)\end{array}$ & $\begin{array}{l}132 \\
(2.9)\end{array}$ & 0.002 \\
\hline COPD & $2,051(9.2)$ & $718(8.8)$ & $885(9.2)$ & $448(10.0)$ & 0.077 \\
\hline Chronic kidney disease & $5,334(23.9)$ & $1,126(13.8)$ & $\begin{array}{l}2,597 \\
(26.9)\end{array}$ & $1,611(35.9)$ & $<0.001$ \\
\hline Diabetes & $3,819(17.1)$ & $1,214(14.8)$ & $\begin{array}{l}1,683 \\
(17.4)\end{array}$ & $\begin{array}{l}922 \\
(20.6)\end{array}$ & $<0.001$ \\
\hline Hypertension & $6,395(28.7)$ & $2,409(29.4)$ & $\begin{array}{l}2,826 \\
(29.3)\end{array}$ & $1,160(25.9)$ & $<0.001$ \\
\hline Number of ICD-10 codes & $12[7 ; 17]$ & $8[5 ; 14]$ & $12[8 ; 18]$ & $16[11 ; 21]$ & $<0.001^{\ddagger}$ \\
\hline Charlson index & $2[0 ; 4]$ & $2[0 ; 4]$ & $2[0 ; 3]$ & $2[1 ; 4]$ & $<0.001^{\ddagger}$ \\
\hline Charlson index categories (\%) & & & & & $<0.001$ \\
\hline 0 & $5,796(26.0)$ & $2,284(27.9)$ & $\begin{array}{l}2,507 \\
(26.0)\end{array}$ & $1,005(22.4)$ & \\
\hline $1-2$ & $8,384(37.6)$ & $3,045(37.2)$ & $\begin{array}{l}3,695 \\
(38.3)\end{array}$ & $1,644(36.7)$ & \\
\hline $3-4$ & $3,953(17.7)$ & $1,229(15.0)$ & $\begin{array}{l}1,725 \\
(17.9)\end{array}$ & $\begin{array}{l}999 \\
(22.3)\end{array}$ & \\
\hline $5+$ & $4,190(18.8)$ & $1,624(19.9)$ & $\begin{array}{l}1,729 \\
(17.9)\end{array}$ & $\begin{array}{l}837 \\
(18.7)\end{array}$ & \\
\hline
\end{tabular}

COPD, chronic obstructive pulmonary disease. Results are expressed as number of patients (column percentage) for categorical variables and as average \pm standard deviation or median [interquartile range] for continuous variables. Between-group comparisons performed using chi-square for categorical variables and analysis of variance or Kruskal-Wallis test $\left.{ }^{\ddagger}\right)$ for continuous variables.

highliers than patients at low risk (Supplementary Table S4). Most associations were confirmed after multivariable analysis (Supplementary Table S5). Further adjusting on ICU stay and LOS led to similar findings, except that 1 -year mortality and the differences between total and reimbursed costs and cost coverage were no longer significant (Supplementary Table S6).

The results of the sensitivity analysis focussing on period 2011-17 are summarised in Supplementary Tables S7S10. Prevalence of intermediate and high risk of frailty 


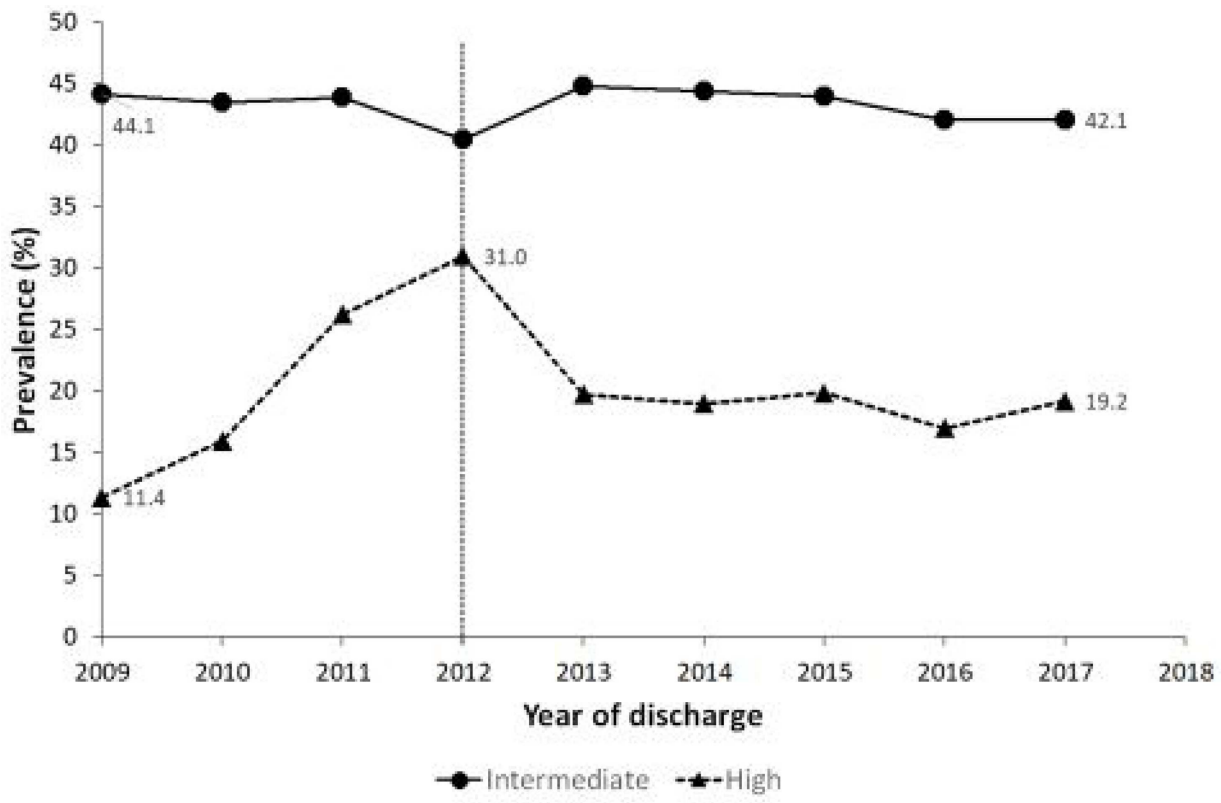

Figure 1. Trends in the prevalence of intermediate and high risk of frailty in the Department of Internal Medicine of the Lausanne University Hospital, 2009-17. Results are expressed as percentage.

Table 2. Bivariate analysis of the associations between frailty risk categories and different outcomes, Lausanne University Hospital, Lausanne, Switzerland, 2009-17

\begin{tabular}{|c|c|c|c|c|}
\hline & Low & Intermediate & High & $P$-value \\
\hline & $\cdots \cdot$ & $\cdots \cdot \cdots \cdot$ & & \\
\hline$N$ & 8,182 & 9,656 & 4,485 & \\
\hline Length of stay (days) & $9.5[6.0 ; 15.0]$ & $12[7.9 ; 18.8]$ & $13.9[9.0 ; 21.9]$ & $<0.001^{\ddagger}$ \\
\hline ICU stay $(\%)$ & $663(8.1)$ & $984(10.2)$ & $537(12.0)$ & $<0.001$ \\
\hline ICU stay (hours) ${ }^{\mathrm{a}}$ & $68[28 ; 120]$ & $97[48 ; 184]$ & $143[61 ; 308]$ & $<0.001^{\ddagger}$ \\
\hline Destination at discharge (\%) & & & & $<0.001$ \\
\hline Deceased & $655(8.0)$ & $783(8.1)$ & $486(10.8)$ & \\
\hline Returned home & $5,413(66.2)$ & $4,351(45.1)$ & $1,403(31.3)$ & \\
\hline Institutionalised & $2,111(25.8)$ & $4,517(46.8)$ & $2,595(57.9)$ & \\
\hline \multicolumn{5}{|l|}{ Mortality (\%) } \\
\hline 30-day & $911(11.1)$ & $1,066(11.0)$ & $628(14.0)$ & $<0.001$ \\
\hline 90-day & $1,474(18.0)$ & $1,822(18.9)$ & $1,035(23.1)$ & $<0.001$ \\
\hline 1 -year & $2,471(30.2)$ & $3,222(33.4)$ & $1,856(41.4)$ & $<0.001$ \\
\hline Readmissions $(N)^{\mathrm{b}}$ & 7,593 & 8,941 & 4,039 & \\
\hline Rate & $280(3.7)$ & $336(3.8)$ & $170(4.2)$ & 0.347 \\
\hline \multicolumn{5}{|l|}{ Costs $(N)^{\mathrm{c}}$} \\
\hline Total (CHF) & $11,161[7,350 ; 17,946]$ & $13,396[8,918 ; 21,972]$ & $15,303[10,359 ; 26,924]$ & $<0.001^{\ddagger}$ \\
\hline Reimbursed (CHF) & $9,553[7,604 ; 14,366]$ & $10,516[8,591 ; 16,518]$ & $11,630[9,419 ; 18,543]$ & $<0.001^{\ddagger}$ \\
\hline Difference $(\mathrm{CHF})$ & $-846[-4,491 ; 2,231]$ & $-2,176[-6,532 ; 1,439]$ & $-3,216[-8,548 ; 1,068]$ & $<0.001^{\ddagger}$ \\
\hline Costs $\geq 70,000 \mathrm{CHF}(\%)$ & $119(1.5)$ & $340(3.5)$ & $304(6.8)$ & $<0.001$ \\
\hline Full coverage $(\%)$ & $2,204(42.8)$ & $2,143(34.8)$ & $923(30.4)$ & $<0.001$ \\
\hline DRG category (\%) & & & & $<0.001$ \\
\hline Lowlier & $157(3.1)$ & $104(1.7)$ & $32(1.1)$ & \\
\hline Inlier & $4,036(78.4)$ & $4,612(74.9)$ & $2,094(68.9)$ & \\
\hline Highlier & $956(18.6)$ & $1,442(23.4)$ & $913(30.0)$ & \\
\hline
\end{tabular}

Results are expressed as number of patients (column percentage) for categorical variables and as average \pm standard deviation or median and [interquartile range] for continuous variables. Between-group comparisons performed using chi-square for categorical variables and analysis of variance or Kruskal-Wallis test $\left({ }^{\ddagger}\right)$ for continuous variables. ${ }^{\mathrm{a} A m o n g}$ patients admitted to ICU. ${ }^{\mathrm{b}}$ Considering the 1 st hospitalisation. ${ }^{\mathrm{c}}$ Data for period 2012-17.

was 43.1 and $22.0 \%$, respectively. On bivariate analysis, patients at intermediate or high risk of frailty were more frequently admitted to the ICU, spent more time in the ICU, were more frequently institutionalised after discharge than patients at low risk, and had higher 30day, 90-day and 1-year mortality than patients at low risk. Patients at intermediate or high risk had a higher total and reimbursed costs, their stay was less frequently 


\section{T. Bonjour et al.}

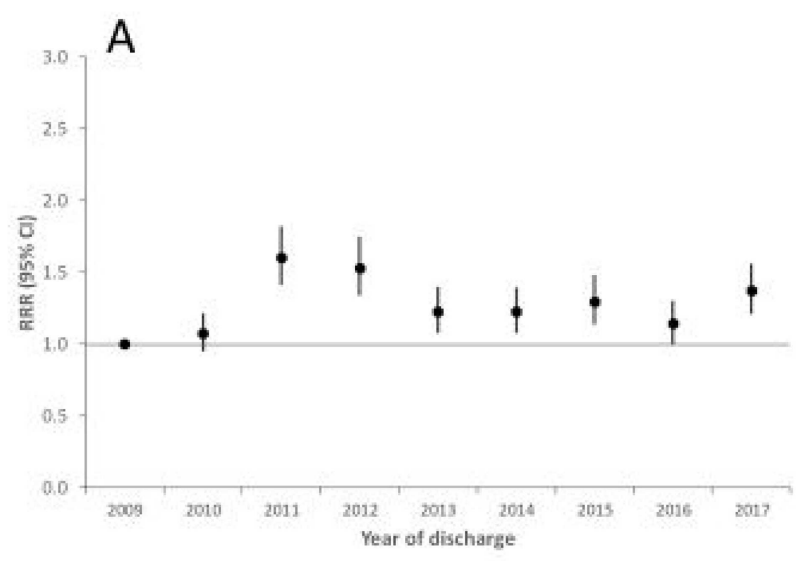

associations were confirmed after multivariable analysis (Supplementary Table S8). Further adjusting on ICU stay and LOS led to similar findings, except that the differences between total and reimbursed costs and cost coverage were no longer significant (Supplementary Tables S9 and S10).

\section{Discussion}

Our results indicate that frailty is a prevalent condition among hospitalised patients and associated with increased hospital costs. Frailty levels appear to be dependent on the coding system of diseases, and the association between frailty and mortality should be further explored.

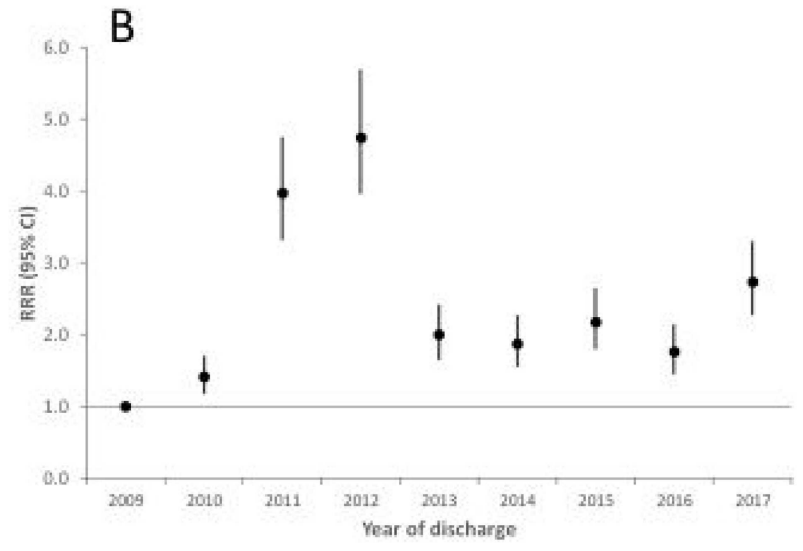

\section{Prevalence and characteristics of frail patients}

Prevalence of intermediate and high risk of frailty was $63 \%$, a value within the range published in a scoping review by Theou et al. [21], where frailty was measured with various scores. However, this prevalence is higher than reported in other studies, ranging from 32 to $40 \%$ [17,22]. A possible explanation would be the hospital setting (university hospital), where patients with multiple comorbidities and possibly more frail could be transferred from other structures.

\section{Evolution of frailty between 2009 and 2017}

Prevalence of high risk of frailty increased from 2009 to 2012, to decrease afterwards. To our knowledge, there is no other study assessing trends in frailty among hospitalised subjects. Interestingly, the decrease in prevalence occurred during the year of DRG implementation in Switzerland. The introduction of the DRG system in Switzerland decreased in-hospital mortality and increased readmission rates, but it did not impact LOS [23] or ICU mortality [24]. Although no study assessed the impact of DRG implementation on disease coding, it is likely that some changes occurred as some ICD codes were no longer valid to calculate DRG and subsequently healthcare reimbursement [25]. Overall, our results suggest that the prevalence of frailty is heavily dependent on the ICD-10 codes used, and that changes in disease coding can lead to considerable changes in the prevalence of frailty.

\begin{tabular}{|c|c|c|c|c|}
\hline & Low & Intermediate & High & $\begin{array}{l}P \text {-value } \\
\text { for trend }\end{array}$ \\
\hline$\cdot \cdot \cdot$ & $\cdots \cdot$ & $\cdot \cdot \cdot \cdot \cdot \cdot$ & $\cdot \cdot \cdot \cdot \cdot \cdot \cdot$ & . . . \\
\hline 30-day & 1 (ref.) & $1.04(0.95-1.14)$ & $1.31(1.16-1.47)$ & $<0.001$ \\
\hline 90-day & 1 (ref.) & $1.04(0.97-1.12)$ & $1.22(1.12-1.34)$ & $<0.001$ \\
\hline 1-year & 1 (ref.) & $1.05(1.00-1.11)$ & $1.21(1.13-1.30)$ & $<0.001$ \\
\hline
\end{tabular}

Results are expressed as multivariable-adjusted relative risk (95\% confidence interval). Between-group comparisons performed using Cox survival analysis adjusted on year of discharge (categorical), gender (man, woman), age group $(65-74,75-84,85+)$, Charlson index categories $(0,1-2,3-4,5+)$, ICU stay (yes, no), number of previous hospitalisations (continuous) and length of stay (quartiles).

fully covered and they were more frequently highliers than patients at low risk, whereas no differences were found regarding rehospitalisation (Supplementary Table S7). These

\section{Association between frailty and LOS, ICU stay, mortality and costs}

Frail patients had a higher likelihood of being admitted in the ICU. These findings are in agreement with a recent study showing an association between frailty (as measured by the HFRS) and unplanned admission to the ICU [26]. A 2nd study also showed an association between frailty (as measured by Clinical Frailty Scale) and short-term mortality in older patients admitted to the ICU [27]. Conversely, another study found no significant association between frailty and adverse outcome after adjusting for disease severity [28]. However, patients in this last study had a very low mean HFRS (31), probably reflecting a severe selection of patients at ICU 
admission. Overall, our results strengthen the evidence of frailty as a risk factor for ICU admission.

Risk of frailty was positively associated with hospital costs, a finding in agreement with a study conducted in a community setting [11]. Risk of frailty was also associated with higher reimbursements, but the increase in reimbursements did not fully compensate the increase in hospital costs. Hence, patients at high risk of frailty led to higher financial losses to the hospital. Given the expected increase in the number of frail, older patients being admitted to the hospital, this finding is of great concern for hospital administrations who face a burden of additional costs. Hence, adequate screening and management of frail patients should be implemented to contain the rising associated costs.

Risk of frailty was not associated with hospital readmission, a finding consistent with a previous study [17], but not with another [22]. Still, in the last study, the association between frailty and readmission only held because early readmissions were included in a composite outcome [22]. Hence, our results do not support the hypothesis that risk of frailty is associated with increased risk of hospital readmission.

We found a significant association of frailty with 1-year mortality, whereas the association with 30-day and 90-day mortality was inconsistent. A positive association between frailty and 30-day mortality has been reported [17]. Several explanations can be put forward to explain this inconsistency. First, it could be explained by a much higher 30 -day mortality (25 versus $12 \%)$ in the high-risk group in the study of Eckart et al. [17] than in the present study. Second, caring of high-risk patients could differ largely between hospitals or even between countries. Overall, our results suggest that frailty is related with 1-year mortality after discharge from hospital, whereas the association with short-term (30- and 90-day) mortality should be further checked.

\section{Strengths and limitations}

The main strengths of our study are the long survey period, which allowed to present trends and evaluation of status at discharge including institutionalisation.

This study also has some limitations. First, it is a monocentric, retrospective, observational study conducted in a Swiss tertiary hospital. Hence, the characteristics of the patients admitted (mostly multimorbid older patients) might not correspond to other settings. Still, the ageing of the population is occurring worldwide, and we believe that our results can be generalisable to most internal unit wards in developed countries. Second, as healthcare and reimbursement systems vary between countries, it is possible that the associations between HFRS and LOS or health costs might also change. Hence, it would be of interest that our findings be replicated in countries with different healthcare or reimbursement systems. Third, our definition of frailty may not reflect true frailty because of being based on comorbidities rather than on measurements such as grip strength. Still, they allow comparing our results with those of studies that used the same methodology $[16,17]$.
Finally, the HFRS calculation is based on the ICD-10 codes from the discharge letter and not on the ICD-10 codes at the admission; furthermore, the coding of the conditions might vary between countries [29]. This can lead to an over- or under-estimation of the frailty risk and complicate between-country comparisons.

\section{Conclusion}

Frailty is frequent among hospitalised patients and is associated with higher hospital costs. The association between frailty and mortality awaits further investigation. This study demonstrates the feasibility of systematic screening for frailty in acute medicine. This could make it possible to improve the care of this population. Future studies investigating the correlation of HFRS with other validated scales in an acute care medicine setting such as CFS should be conducted.

Supplementary Data: Supplementary data mentioned in the text are available to subscribers in Age and Ageing online.

Declaration of Conflicts of Interest: None.

Declaration of Sources of Funding: None.

\section{References}

1. Department of Economic and Social Affairs. World Population Projected to Reach 9.8 Billion in 2050, and 11.2 Billion in 2100. New York, USA, 2017. https://www.un.org/ development/desa/en/news/population/world-populationprospects-2017.html (May 2020, date last accessed).

2. Kohli R. Scénarios de l'évolution de la population des cantons. Neuchâtel, Switzerland: Federal Office of Statistics, 2016; Contract No.: 870-1500-03.

3. Clegg A, Young J, Iliffe S, Rikkert MO, Rockwood K. Frailty in elderly people. Lancet 2013; 381: 752-62.

4. Rockwood K, Song X, Mac Knight C et al. A global clinical measure of fitness and frailty in elderly people. CMAJ 2005; 173: 489-95.

5. Gilardi F, Capanna A, Ferraro $M$ et al. Frailty screening and assessment tools: a review of characteristics and use in public health. Ann Ig 2018; 30: 128-39.

6. Collard RM, Boter H, Schoevers RA, Oude Voshaar RC. Prevalence of frailty in community-dwelling older persons: a systematic review. J Am Geriatr Soc 2012; 60: 1487-92.

7. Song X, Mitnitski A, Rockwood K. Prevalence and 10-year outcomes of frailty in older adults in relation to deficit accumulation. J Am Geriatr Soc 2010; 58: 681-7.

8. Kojima G, Iliffe S, Walters K. Frailty index as a predictor of mortality: a systematic review and meta-analysis. Age Ageing 2018; 47: 193-200.

9. Kojima G, Iliffe S, Morris RW et al. Frailty predicts trajectories of quality of life over time among British community-dwelling older people. Qual Life Res 2016; 25: 1743-50.

10. Hubbard RE, Peel NM, Samanta M, Gray LC, Mitnitski A, Rockwood K. Frailty status at admission to hospital predicts multiple adverse outcomes. Age Ageing 2017; 46: 801-6. 


\section{T. Bonjour et al.}

11. Garcia-Nogueras I, Aranda-Reneo I, Pena-Longobardo LM, Oliva-Moreno J, Abizanda P. Use of health resources and healthcare costs associated with frailty: the FRADEA study. J Nutr Health Aging 2017; 21: 207-14.

12. Comans TA, Peel NM, Hubbard RE, Mulligan AD, Gray LC, Scuffham PA. The increase in healthcare costs associated with frailty in older people discharged to a post-acute transition care program. Age Ageing 2016; 45: 317-20.

13. Santos-Eggimann B, Sirven N. Screening for frailty: older populations and older individuals. Public Health Rev 2016; 37: 7.

14. Fried LP, Tangen CM, Walston J et al. Frailty in older adults: evidence for a phenotype. J Gerontol A Biol Sci Med Sci 2001; 56: M146-56.

15. Mitnitski AB, Mogilner AJ, Rockwood K. Accumulation of deficits as a proxy measure of aging. Sci World J 2001; 1: 323-36.

16. Gilbert T, Neuburger J, Kraindler J et al. Development and validation of a Hospital Frailty Risk Score focusing on older people in acute care settings using electronic hospital records: an observational study. Lancet 2018; 391: 1775-82.

17. Eckart A, Hauser SI, Haubitz S et al. Validation of the Hospital Frailty Risk Score in a tertiary care hospital in Switzerland: results of a prospective, observational study. BMJ Open 2019; 9: e026923.

18. Sundararajan V, Quan $H$, Halfon $P$ et al. Cross-national comparative performance of three versions of the ICD-10 Charlson index. Med Care 2007; 45: 1210-5.

19. Charlson ME, Pompei P, Ales KL, MacKenzie CR. A new method of classifying prognostic comorbidity in longitudinal studies: development and validation. J Chronic Dis 1987; 40: 373-83.

20. Martin PY, Burnier M. Dialysis....at what cost? Rev Med Suisse 2005; 1: 531-2.
21. Theou O, Squires E, Mallery $\mathrm{K}$ et al. What do we know about frailty in the acute care setting? A scoping review. BMC Geriatr 2018; 18: 139.

22. Kahlon S, Pederson J, Majumdar SR et al. Association between frailty and 30-day outcomes after discharge from hospital. CMAJ 2015; 187: 799-804.

23. Kutz A, Gut L, Ebrahimi F, Wagner U, Schuetz P, Mueller B. Association of the Swiss Diagnosis-Related Group reimbursement system with length of stay, mortality, and readmission rates in hospitalized adult patients. JAMA Netw Open 2019; 2: e188332.

24. Chok L, Bachli EB, Steiger P et al. Effect of Diagnosis Related Groups implementation on the intensive care unit of a Swiss tertiary hospital: a cohort study. BMC Health Serv Res 2018; 18: 84.

25. Vonzun N, Ruhlin M, Sterchi A. Malnutrition in the era of DRG. Ther Umsch 2014; 71: 185-9.

26. Redfern OC, Harford M, Gerry S, Prytherch D, Watkinson PJ. Frailty and unplanned admissions to the intensive care unit: a retrospective cohort study in the UK. Intensive Care Med 2020; 46: 1512-3.

27. Guidet B, de Lange DW, Boumendil A et al. The contribution of frailty, cognition, activity of daily life and comorbidities on outcome in acutely admitted patients over 80 years in European ICUs: the VIP2 study. Intensive Care Med 2020; 46: 57-69.

28. Bruno RR, Wernly B, Flaatten H, Scholzel F, Kelm M, Jung C. The Hospital Frailty Risk Score is of limited value in intensive care unit patients. Crit Care 2019; 23: 239.

29. Quan H, Moskal L, Forster AJ et al. International variation in the definition of 'main condition' in ICD-coded health data. Int J Qual Health Care 2014; 26: 511-5.

Received 24 August 2020; editorial decision 30 November 2020 